\title{
A CRISE ECONÔMICA DO SUBPRIME E OS IMPACTOS FINANCEIROS NO SETOR AUTOMOTIVO BRASILEIRO
}

\section{CRISIS AND ECONOMIC IMPACTS OF SUBPRIME FINANCIAL SECTOR IN BRAZILIAN AUTOMOTIVE}

\section{SOARES, Geogeane S*, LIMA, José E. C.}

Faculdade Leão Sampaio, Juazeiro do Norte (CE), Brasil.

Recebido em: 09/05/2014; aceito: 04/09/2014; publicado em 19/11/2014

\section{RESUMO}

Esta pesquisa teve como objetivo analisar os impactos financeiros da crise econômica do subprime no setor automotivo brasileiro. Diante da potencialidade e relevância do setor para a economia brasileira, observou-se que o mesmo apresentou resultados positivos, quando comparado com o mesmo setor de países Europeus, Estados Unidos e Japão. Logo surgiram as indagações quanto a real saúde econômica desse setor no país. Neste contexto, este estudo se propôs a examinar de forma objetiva, 7 ações do setor, no período compreendido entre janeiro de 2006 e dezembro de 2010, visando obter resultado satisfatório as hipóteses levantada neste estudo. Para tanto buscou-se tais resoluções através de pesquisa bibliográfica, a partir de fontes secundários, de natureza quanti-qualitativa, por meio dos índices de performance sharpe e sortino. Para fim desta averiguação utilizou-se como benchmark o IBOV, largamente usado como parâmetro de análise.

Palavras-chave: Setor Automotivo. Crise Econômica. Subprime. Sharpe. Sortino

\begin{abstract}
This research aims to analyze the financial impacts of the economic crisis in the subprime Brazilian automotive sector. Given the potential and relevance of the sector for the Brazilian economy, it was observed that it presented positive results, when compared to the same sector of European, United States. and Japan countries. inquiries as real economic health of this sector in the country emerged. In this context, this study aimed to examine objectively, 7 shares of the sector in the period between January 2006 and December 2010, in order to obtain satisfactory results the hypotheses raised in this study. For this we sought such resolution through a literature review, based on secondary sources, quantitative and qualitative in nature, through the sharpe ratios and sortino. To order this investigation was used as the benchmark ibov widely used as a parameter for analysis.
\end{abstract}

Keywords: Automotive. Economic Crisis. Subprime. Sharpe. Sortino. 


\section{INTRODUÇÃO}

O Brasil, classificado como país emergente vem apresentando crescimento econômico desde 1994, a partir do lançamento do plano real. O plano foi adotado visando controlar a inflação que foi responsável por grandes transtornos e problemas econômicos e financeiros no país.

Foi com o plano real, que o país passou a viver uma nova fase econômica. O país passou a ter maior controle da inflação, a população passou a ter maior poder de compra e várias famílias brasileiras saíram do estado de pobreza extrema, gerando grande expectativa para essas famílias, que provocou efeito cascata, impactando positivamente a economia do país.

Mas foi com o estouro da bolha de hipotecas imobiliárias nos Estados Unidos, em 2007 que rapidamente se transformou em uma crise financeira, afetando a economia de vários países, inclusive a do Brasil, porém visando manter o aquecimento da economia brasileira foi que o governo adotou medidas protecionistas, beneficiando alguns setores da economia, especialmente o setor automotivo.

Neste contexto foi que surgiram vários questionamentos quanto aos impactos da crise econômica mundial no setor automotivo brasileiro, foi a partir dessas indagações que se questionou o quanto o setor foi afetado e qual a intensidade: i) $\mathrm{O}$ setor automotivo brasileiro teve crescimento em meio à crise econômica? ii) As políticas econômicas adotadas pelo governo tem se mostrado eficiente em termos de manter o setor acelerado? iii) Por que muitos acreditam que a crise pode ser uma grande oportunidade para os países emergentes entre eles o Brasil?

Diante desta temática é que foi desenvolvida esta pesquisa.

\section{REFERENCIAL TEÓRICO}

\subsection{HISTÓRICO DA INDÚSTRIA AUTOMOBILÍSTICA NO BRASIL}

O Brasil desde a década de 30, já apresentava um grande potencial no setor automobilístico, onde já contava com duas grandes montadoras: a FORD e a General Motors, mas foi em 1956, que o presidente Juscelino Kubitschek, um homem visionário, adotou políticas visando à criação do parque industrial automotivo, onde foi criado o GEIA Grupo Executivo da Indústria Automobilística, objetivando expandir o setor no Brasil. ${ }^{1}$

No final dos anos 90, grandes marcas como Volkswagen, FORD, FIAT e Chevrolet, já dominavam o mercado automotivo brasileiro, além destas, marcas como a Renault, Peugeot e Citroen também instalariam fábricas no Brasil. Já as empresas $100 \%$ brasileiras que tentaram investir no setor automotivo como a Miura, Gurgel e a Puma não sobreviveram e umas das últimas nacionais como a Troller foi comprada pela FORD. ${ }^{2}$

Neste contexto, é oportuno salientar que Juscelino Kubitschek quando em 1956 criou o GEIA, não imaginava o impacto positivo que seria para o país, onde atualmente está entre os maiores produtores de veículos automotores do mundo, com aproximadamente 26 montadoras, varias unidades fabris e com capacidade produtiva para mais de 4 milhões de veículos, gerando aproximadamente $140 \mathrm{mil}$ empregos diretos. ${ }^{1}$

\subsection{CRISE SUBPRIME}

Aos primeiros sinais de crise em 2007, no setor de construção e de hipotecas imobiliárias, o mercado teve reação de descrença. Naquela ocasião o presidente do Banco Central americano falou para o Congresso, que "na atual conjuntura, o impacto dos problemas do mercado de hipotecas subprime na economia mais ampla e nos mercados financeiros parece que deve ser contido" Em outro momento o secretário do Tesouro americano desconsiderou um possível colapso das hipotecas imobiliárias. ${ }^{3}$

Para muitos a crise subprime era impossível prever, no entanto crises surgem de forma metódica, seguindo um percurso semelhante as já ocorridas, onde é perfeitamente previsível, sendo que são decorrentes de sequências de vulnerabilidades econômicas e financeiras, gerando um ponto de desestabilização. ${ }^{3}$

Neste contexto a avaliação feita pelo Banco Central brasileiro não era animadora, para o cenário econômico mundial, onde o diretor de políticas econômicas daquela instituição, afirmou em entrevista a revista Valor Econômico que "a única certeza é que há mais dúvidas agora, sobre o 
que ocorrerá na economia mundial, do que existia há três meses". 1

Logo a crise do subprime tem sido considerada a maior crise desde Grande Depressão em 1929, gerando desconfiança no mercado financeiro, onde quem tem dinheiro não empresta, gerando estagnação na economia por falta do giro da moeda. ${ }^{4}$

Diante de erros econômicos e financeiros cometidos pelo sistema financeiro a crise de 2008, se tornou o produto final dos desequilíbrios, gerado pelas transações com derivativos, os quais eram facilmente aceitos pelas instituições por apresentar grande rentabilidade financeira, no entanto o problema da falta de regulação era real e deu margens para os erros que culminaram em uma das maiores crises no cenário econômico mundial. ${ }^{5}$

Logo a crise subprime contagiou todo o sistema financeiro internacional. O ano de 2007 foi marcado pela falta dos pagamentos das hipotecas, que se alastraram, ocasionando concordatas e falências nas instituições especializadas do setor. Não tardaria até que o sistema financeiro começasse a sentir os impactos do subprime. À medida que o crédito mundial perdia o ritmo e começava a desacelerar, e todo esse processo se deu conforme as economias descobriam que seus investimentos eram derivados de hipotecas subprime. ${ }^{6}$

\subsubsection{Causas da crise subprime segundo a visão de pinheiro $^{4}$}

Haja vista que o mercado imobiliário americano apresentava alta rentabilidade em 2000, foi que os dois gigantes do setor: Fannie Mae e Freddie Mac compraram aproximadamente US\$ 19 bilhões em hipotecas e empréstimos subprime, facilitando crédito a indivíduos inadimplentes elevando os riscos que envolvem dá crédito a quem não pode pagar.

Neste contexto econômico e político a NBER realizou uma pesquisa e concluiu que a economia americana estava em recessão causada pelas empresas “pontocom”. O Federal Reserve (Fed) visando conter a recessão reduziu a taxa de juros a $1 \%$ a.a., visto não surtir efeito, em junho de 2003, além da redução da taxa de juros, se iniciou a flexibilidade da taxa básica, objetivando desonerar os empréstimos e aquecer o consumo interno que estava passando por processos de desaceleração com a crise da “internet”. Por ocasião da política de redução da taxa de juros adotada em 2001 pelo governo, houve um expressivo crescimento no setor imobiliário, o que alimentava gradativamente a bolha imobiliária.

Ainda em 2003, com a taxa de juros em baixa, o mercado imobiliário atingiu o topo, porém em 2004, as taxa de juros voltaram a crescer, a fim de conter a inflação, saltando de $1 \%$ a.a. para 5,35\% a.a., mas foi em 2005, que ocorreu a grande expansão da linha subprime, onde se valorizou as taxas de retorno das transações com títulos imobiliários, o que atraiu grandes investidores e bancos americanos e europeus, culminando em uma cadeia especulativa de venda desses títulos.

Como todo processo evolutivo foi em 2006, que se iniciou o declínio do setor imobiliário, o qual não possuía bases sólidas para resistir por mais tempo, os preços dos imóveis já não eram mais tão atrativos, a elevação da taxa de juros, que tornava inviável a negociação devido ao elevado custo do crédito, com isso o índice de inadimplentes aumentou consideravelmente, afastando os consumidores, gerando grande impacto nos títulos do mercado imobiliário.

Diante da desaceleração do crédito nos EUA, começou pairar clima de desconfiança nos principais investidores da Europa, que os levara a adotar medidas de prevenção, que gerou grande tumultuo culminando em uma das maiores crise financeiras mundiais.

\subsubsection{O cenário econômico brasileiro durante a crise}

No primeiro semestre de 2008, o Brasil vivia uma situação singular onde as reservas internacionais atingiram o montante histórico de US\$ 206,8 bilhões, com variação de $14,7 \%$ sobre o exercício anterior, que foi de US\$ 180,3 bilhões. $^{7}$

A Bovespa apresentou uma receita operacional de R\$ 1.783,4 milhões em 2008, devido os mercados apresentarem um cenário bastante positivo, porém em 2009 o cenário de quedas nas ações, causado por investidores inseguros que venderam seus títulos, gerando uma grande fuga de capitais, que resultou em uma receita operacional de R\$ 1.672,9 milhões com uma queda de 6,2\% em comparação ao ano anterior. ${ }^{8}$ 
As vendas no setor automobilístico que tinha uma projeção de crescimento de $20 \%$ em 2008 , em comparação com o ano anterior, caíram bruscamente nos últimos meses do ano, entretanto fechando o ano com acumulado abaixo do previsto, mas com saldo positivo de 7,9\%. Com as projeções de vendas frustradas e o cenário claro de desaceleração no setor, gerou-se a elevação dos estoques nas concessionárias e fábricas, onde as montadoras já davam sinal de que iriam alinhar a produção a demanda, o que desencadearia redução no PIB e no numero de empregos gerados por esse setor. ${ }^{1}$

Neste contexto o ano de 2009 foi marcado pelas reduções de juros levando ao fortalecimento do crescimento do crédito, onde as projeções do crédito poderiam alcançar até $45 \%$ do PIB do país até o final do exercício. ${ }^{1}$

Já no acumulado final de 2009 o setor automobilístico apresentou crescimento de $1,17 \%$ na produção de automóveis, no entanto não aconteceu o mesmo com os demais segmentos, registrando decréscimo de -1,02 no acumulado geral. Entretanto o cenário externo o resultado foi por devera preocupante, onde as exportações apresentou um decréscimo de $-35,29 \%$. $^{9}$

Diante da confiança do consumidor logo percebe-se que em 2010 as exportações no setor automobilístico apresentaram crescimento de $61,45 \%$, comparado ao ano anterior. $\mathrm{O}$ setor teve crescimento de 14,55\%, principalmente na produção de caminhões e ônibus. ${ }^{9}$

\subsection{VEÍCULOS, TRANSPORTES E AUTOPEÇAS}

O setor automobilístico brasileiro ocupa as maiores posições no ranking mundial, comportando em seu território 3.994 concessionarias de automóveis e 1.122 de máquinas agrícolas automotrizes, onde tem a representação das maiores marcas do mundo, além desse cenário, ano após ano esses números crescem para atender a demanda interna do mercado brasileiro. ${ }^{9}$

Com esse panorama no setor automobilístico notase, sua importância para a economia brasileira, no que se refere ao volume faturado e na sua participação no produto interno bruto industrial anual, o qual apresenta índice de crescimento, mesmo em período de intensa crise na economia mundial, vejamos o gráfico 01 :
Gráfico 01: Relação do faturamento do setor automotivo e o percentual de participação no PIB brasileiro

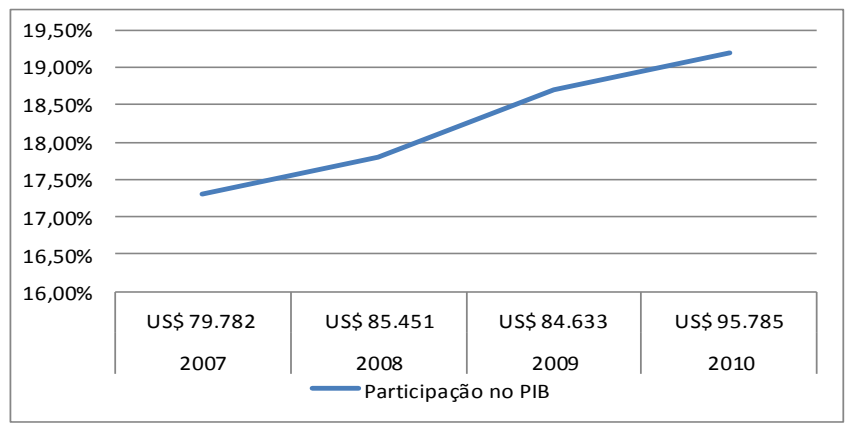

Fonte: ANFAVEA, 2013

Diante de um cenário econômico mundial desconfiado e receoso no período de pré-crise, crise e póscrise, que compreende os anos de 2007 a 2010, foram investidos no setor automobilístico brasileiro aproximadamente US\$ 11.926 (Onze milhões e novecentos e vinte e seis mil dólares), visando manter o setor acelerado e competitivo. ${ }^{9}$

Quanto à balança comercial referente ao setor automobilístico no período que compreende de 2007 a 2010, apresentou certa disparidade, onde o Brasil importou mais do que exportou. Em 2010 o setor atingiu a casa dos US\$ 18.247 (Dezoito milhões e duzentos e quarenta e sete mil dólares), em importação, diante desse cenário se torna notável que a economia ainda se recupera dos abalados sofridos pela crise subprime, situação que pode demandar tempo para recuperação total. ${ }^{9}$

No que se refere à balança comercial o setor de autopeças não foi muito diferente do setor automobilístico, e percebeu-se de igual forma que houve mais importação do que exportação, ao longo do período compreendido entre 2007 a 2010, porém vale ressaltar que de 2008 a 2010 a balança comercial teve seus piores resultados entre a diferença da exportação e importação, onde é oportuno destacar que em 2010, o resultado para menor foi de aproximadamente US\$ 3.546,8 (Três milhões e quinhentos e quarenta e seis dólares e oito centavos), com esses resultados, percebe-se o quanto o mercado externo recuou em termos de investimentos. ${ }^{10}$

Quando observado o trajeto do setor automobilístico brasileiro, a partir de 2004 percebe-se que o mesmo passava por momento de crescimento na produção de autoveículos conforme gráfico 02 : 
Gráfico 02 - Total da produção de autoveículos montados e desmontados no Brasil, entre 1997 e 2012.

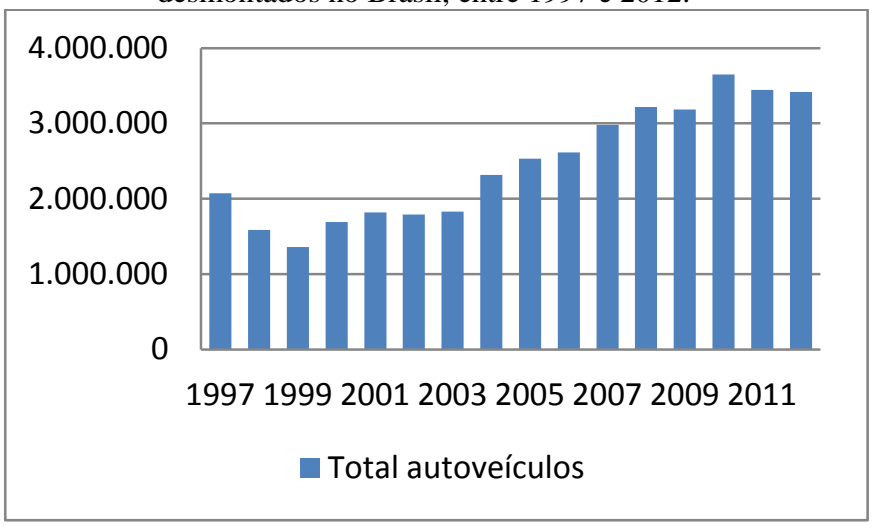

Fonte: ANFAVEA, 2013

Foi a partir do início da crise imobiliária nos EUA, que países Europeus e o Japão começaram a sentir as consequências da crise na produção de veículos, devido à desconfiança dos investidores, que logo afetou o crédito no mercado, no entanto, o cenário externo não afetou de imediato a economia brasileira, o que evitou a desaceleração na produção, onde parte desses resultados se deve as medidas anticíclicas adotadas pelo governo federal, nas quais contemplavam a isenção do IPI beneficiando principalmente o setor automotivo. ${ }^{9}$

Se analisado o setor em uma linha do tempo podese acompanhar a escala de produção de veículos montados no Brasil, tanto de modo geral como por categoria de veículos conforme gráfico 03 :

Gráfico 03 - Produção de autoveículos montados e desmontados por segmento no Brasil, entre 1997 e 2012.

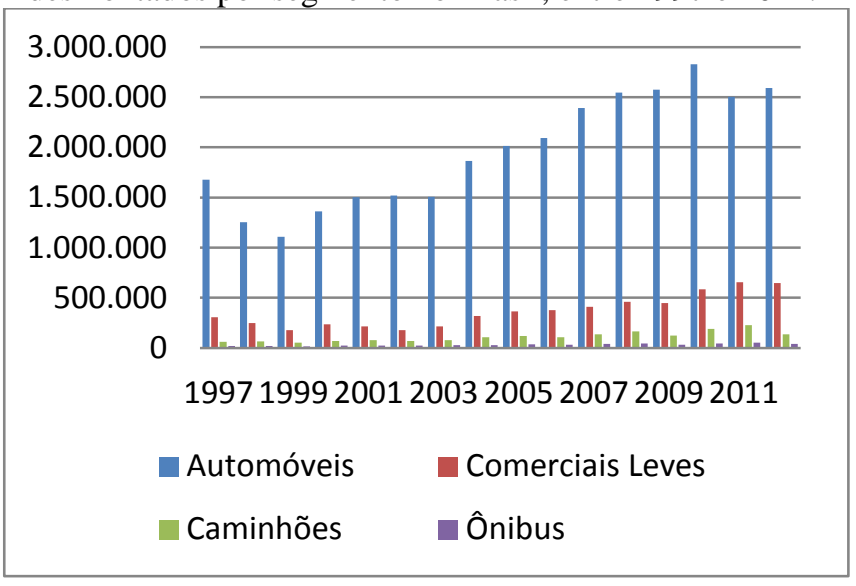

Fonte: ANFAVEA, 2013

Diante desse cenário o setor automobilístico tornase mais atento ao comportamento do mercado, entretanto no período de pré-crise, crise e pós-crise o setor obtive resultados positivos se comparado com o mercado externo. ${ }^{9}$

\section{METODOLOGIA}

Objetivando responder as questões levantadas nesta pesquisa, buscou-se através de pesquisa bibliográfica, a partir de fontes secundárias, de natureza quanti-qualitativa por meio de análises de desempenho, resultados que possibilitasse o entendimento do objeto principal deste estudo que é a crise econômica mundial do subprime e os impactos financeiros no setor automotivo brasileiro.

Para fim desta pesquisa foram utilizadas ações do banco de dados do Yahoo Finanças e da Bovespa.

Logo para efeitos desta pesquisa, foram analisadas as ações das seguintes empresas do setor automotivo brasileiro: Ford (F), Toyota (TM), Caterpillar (CAT. MX), Fras-Le (FRAS4), Honda (HMC), Randon (RAPT4.SA) e Iochpe (IOCJY), as quais foram selecionadas a partir da relevância para o setor em questão. As ações estão divididas da seguinte forma: 4 ações pertencem as empresas fabricantes de autoveículos, 2 ações as empresas fabricantes de autopeças e 1 empresa fabricante de máquinas agrícolas automotrizes, englobando assim todos os segmentos do setor.

A partir dessas ações foram realizadas analises diárias das cotações, utilizando indicadores de performance no período compreendido de 2006 a 2010, logo foram divididos em 10 períodos semestrais os quais engloba os períodos de pré-crise que compreende de janeiro de 2006 a dezembro de 2007, crise, que compreende de janeiro de 2008 a dezembro de 2008 e pós-crise, que compreende de janeiro de 2009 a dezembro de 2010.

Para efeito deste estudo foi utilizado como benchmark o índice da Bovespa e como ativo livre de risco a Poupança. A partir dos resultados obtidos foram realizadas análises visando demonstrar o comportamento das ações no auge da crise subprime.

\section{1 ÍNDICES DE PERFORMANCE DE ATIVOS FINANCEIROS}

O princípio da diversificação de Markowitz influenciou grandemente o mercado financeiro, levando os agentes econômicos apostarem em maiores retornos considerando certo nível de risco, a partir deste cenário 
torna-se relevante os modelos de avaliação de desempenho de investimentos, sendo que as medidas estão correlacionadas ao alinhamento do retorno esperado e ao risco assumido dos retornos. ${ }^{5}$

\subsection{1 Índice de Sharpe}

Considerando as métricas existentes para avaliação e acompanhamento dos desempenhos destaca-se o índice de Sharpe (ISH), o qual pode ser vantajoso em termos de assimilação desta forma de medida sendo que pode ser calculado diretamente em uma série temporal com um dado ativo financeiro, sem necessitar de informações préexistentes do ativo. Outro ponto relevante é a questão deste índice poder calcular tantos ativos individuais, quanto portfólios. ${ }^{1}$ (MATOS; SOARES, 2010).

Esta importante métrica consiste na relação entre o retorno excedente do valor investido no ativo em evidência e a medida da sua volatilidade pelo desvio padrão. ${ }^{5}$ (VARGAS, 2001 apud LIMA, 2012).

Logo a relação para representar o índice de Sharpe do ativo $i$ :

$$
\operatorname{ISH}\left(r_{t}^{i}\right)=\frac{E\left(r_{t}^{i}\right)-{ }_{r}{ }^{f}}{\sigma\left(r_{t}^{i}\right)}
$$

Onde, $\left(r_{t}^{i}\right)$ trata do retorno nominal real líquido do ativo no período $t, E\left(r_{t}^{i}\right)$ o retorno esperado para o ativo $\sigma\left(r_{t}^{i}\right)$ corresponde ao desvio-padrão para este retorno e $-{ }_{r}^{f}$ refere-se ao retorno nominal da taxa livre de risco. ${ }^{1}$

Neste contexto, percebe-se que existem críticas quanto à eficiência desta métrica estatística em relação à percepção do comportamento do investidor quanto as diferentes reações diante as informações positivas ou negativas de mesma relevância ou ganhos e perdas de valores assemelhados. Os investidores temem as oscilações quando estas trarão perda de liquidez e não em ganhos, logo nem todas as oscilações denota cenário de preocupação, pois nem toda incerteza significa risco. ${ }^{1}$
Na década de 80 o índice de sortino foi proposto, onde está métrica de acompanhamento ou performance objetivava oferecer um valor para a compensação do lucro adicional em relação a um benchmark tido como menos interessante por unidade de risco assimétrica a qual puni somente os desvios abaixo da média. ${ }^{1}$

O Downside Risk utiliza o retorno mínimo aceitável (RMA) como ponto de referencia considerando apenas os retornos abaixo dele. Neste contexto o RMA é a unidade definido pelo investidor para usá-lo como variável RMA do próprio benchmark. ${ }^{5}$

Logo, o ISor é expresso da seguinte forma:

$$
\text { ISor }=\begin{gathered}
E\left[r_{t}^{i}\right]-R M A \\
\text { Downside Risk }
\end{gathered}
$$

$$
\text { ISor }=\frac{E\left[r_{t}^{i}\right]-R M A}{\sqrt{\frac{1}{t} \sum_{t}^{n}=0\left[\min \left(r_{i}^{t}-R M A ; 0\right)\right]^{2}}}
$$

Onde, $E\left[r_{t}^{i}\right]$ é o retorno esperado do portfolio. Neste contexto a relação de cálculo de downside risk se da pela forma:

Downside Risk $=$

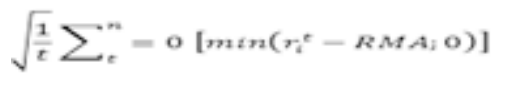

Onde será determinado o retorno mínimo aceitável do objeto de estudo deste trabalho.

\section{ANÁLISE DOS RESULTADOS}

Diante de um cenário de crise o qual afetou todo o sistema financeiro mundial, e consequentemente as economias, e uma vez que se acreditava que os países emergentes, entre eles o Brasil, não teriam maiores problemas, já que esses não possuíam títulos de alto risco "subprime", no entanto, partindo do princípio que a globalização interliga todas as economias e considerando ainda que o sistema financeiro é interligado entre si, seja de forma, direta ou indireta, o que acaba elevando o risco de contágio financeiro e econômico consideravelmente para todos os países.

Considerando a importância do setor automotivo para economia brasileira, viu-se a necessidade de analisar os 
possíveis impactos da crise subprime nesse setor. Para a análise de desempenho das ações estudadas, as cotações foram dividas por semestre, visando objetividade $\mathrm{e}$ eficiências nessas análises. Para se obter resultados robustos foi analisado o desempenho das ações por meio de índices, em um período que englobasse todas as fases da crise.

As análises realizadas através dos índices de Sharpe e Sortino apontam que à ação HMC, apresentou queda de 0,2021 em seu desempenho no segundo semestre de 2006, apresentando uma leve recuperação no semestre seguinte, porém no acumulado ainda apresentava resultados abaixo do esperado pelo mercado. Já a ação CAT.MX no segundo semestre de 2006, apresentou o melhor desempenho das ações analisadas com resultado de 0,0905 de acordo com o índice de Sharpe, no entanto no primeiro semestre de 2007, esta mesma ação teve uma queda de mais de $100 \%$, fechando em -0,093, ela estava entre as quatro ações com pior desempenho das empresas analisadas.

A RAPT4.SA, vinha apresentando desempenho negativo desde o primeiro semestre de 2006, porém em 2007.1, foi a ação com pior desempenho entre as analisadas, fechando em $\quad-0,3208$ mensurado pelo índice de Sortino e -0,2416 quantificado pelo índice de Sharpe. Analisando a ação FRAS4, percebe-se a discrepância na sua performance capturada pelos índices de Sharpe e Sortino, onde uma apresenta queda de $-0,0596$ e a outra de -0,2000, respectivamente no segundo semestre de 2006, onde apresentou leve recuperação no segundo semestre de 2007, fechando em 0,0252 de acordo com índice de Sharpe, conforme demonstram as tabelas 1 e 2 :

Tabela 1: Estatísticas descritivas básicas das ações do setor automotivo do período entre janeiro e junho de 2006

\begin{tabular}{|l|ccccccc}
\hline \multicolumn{1}{c}{} & \multicolumn{7}{c}{ Ações } \\
\cline { 2 - 8 } \multicolumn{1}{c|}{ CAT.MX } & RAPT4.SA & FRAS4 & I0CJY & F & TM & HMC \\
\hline Sharpe & $-0,0549$ & 0,0258 & $-0,0057$ & $-0,0779$ & 0,0365 & $-0,0137$ & $-0,0611$ \\
Sortino (Downside Risk) & $-0,1041$ & 0,0014 & $-0,1933$ & $-0,0732$ & $-0,0049$ & $-0,0842$ & $-0,0778$ \\
\hline
\end{tabular}

Fonte: Elaboração da Autora

Tabela 2: Estatísticas descritivas básicas das ações do setor automotivo do período entre julho e dezembro de 2006

\begin{tabular}{l|ccccccc}
\hline \multicolumn{1}{c}{} & \multicolumn{7}{c}{ Ações } \\
\cline { 2 - 8 } \multicolumn{1}{c|}{} & CAT.MX & RAPT4.SA & FRAS4 & IOCJY & F & TM & HMC \\
\hline Sharpe & 0,0905 & $-0,1460$ & $-0,0596$ & 0,0327 & $-0,0357$ & $-0,1781$ & $-0,1381$ \\
Sortino (Downside Risk) & 0,0367 & $-0,2076$ & $-0,2000$ & $-0,0464$ & $-0,1128$ & $-0,2312$ & $-0,2021$ \\
\hline
\end{tabular}

Fonte: Elaboração da Autora.
Já a ação F diferentemente das demais apresentou desempenho abaixo do esperado no primeiro semestre de 2007, de -0,1206 de acordo o índice de Sharpe e de -0,1809 de acordo com índice de Sortino, percebido uma leve recuperação no desempenho no semestre subsequente. $\mathrm{O}$ desempenho da ação IOCJY de acordo com o índice de Sharpe apresentou no segundo semestre de 2006, desempenho positivo de 0,0327 , porém essa ação sofre uma queda, fechando em -0,1497, no primeiro semestre de 2007, já no semestre seguinte apresentou uma leve recuperação, mas não atingindo os resultados esperado pelo mercado, conforme tabela 3:

Tabela 3: Estatísticas descritivas básicas das ações do setor automotivo do período entre janeiro e junho de 2007

\begin{tabular}{l|ccccccc}
\hline & \multicolumn{7}{c}{ Ações } \\
\cline { 2 - 8 } & CAT.MX & RAPT4.SA & FRAS4 & IOCJY & F & TM & HMC \\
\hline Sharpe & $-0,0903$ & $-0,2416$ & $-0,0443$ & $-0,1497$ & $-0,1206$ & 0,0269 & 0,0389 \\
Sortino (Downside Risk) & $-0,0855$ & $-0,3208$ & $-0,0985$ & $-0,1970$ & $-0,1809$ & $-0,0561$ & $-0,0410$ \\
\hline
\end{tabular}

Fonte: Elaboração da Autora.

Analisando de forma sistêmica percebe-se que as ações FRAS4, CAT.MX, RAPT4.SA, IOCJY e F, apresentaram desempenho abaixo do esperado no primeiro semestre de 2007, onde dessas apenas a IOCJY não apresentou recuperação relevante no segundo semestre de 2007. Um fator a ser considerado é de que o ano de 2007 pelo estouro da bolha de hipotecas nos EUA, onde de forma indireta pode ter afetado os resultados de desempenho dessas ações no mercado, conforme tabela 4:

Tabela 4: Estatísticas descritivas básicas das ações do setor automotivo do período entre julho e dezembro de 2007

\begin{tabular}{l|ccccccc}
\hline & \multicolumn{7}{c}{ Ações } \\
\cline { 2 - 8 } & CAT.MX & RAPT4.SA & FRAS4 & IOCJY & F & TM & HMC \\
\hline Sharpe & 0,0720 & 0,0078 & 0,0252 & $-0,0673$ & 0,1143 & 0,0965 & 0,0523 \\
Sortino (Downside Risk) & 0,1274 & $-0,0462$ & $-0,0267$ & $-0,1027$ & 0,0888 & 0,0132 & 0,0028 \\
\hline
\end{tabular}

Fonte: Elaboração da Autora.

Neste contexto, percebeu-se que a crise subprime que teve seu auge em 2008, ou seja, o período em que a crise se alastrou por todo o sistema financeiro e econômico. Foi nesse cenário que algumas ações do setor automotivo apresentava melhor desempenho do que o IBOV, índice utilizado como parâmetro de análise, com isso nota-se a distorção entre os desempenhos das ações do setor e a situação econômica no âmbito interno e externo do país, diante desses resultados, fatores que podem justificar esse comportamento do desempenho das ações no segundo semestre de 2008, se deu devido a intervenção do governo, 
com políticas fiscais e econômicos, visando manter aquecido a economia, principalmente o setor automotivo brasileiro que é peça importante no contexto econômico do país.

Contanto, após a alta no desempenho das ações no segundo semestre de 2008, vem a queda na performance dessas ações, facilmente percebida, no primeiro e segundo semestre de 2009, tal comportamento se deve a grande recessão em que o mundo passava, causada pela falta de confiança dos investidores, que mesmo diante dos incentivos e pacotes de socorro utilizado pelo governo, não foi suficiente para impedir a fuga de capitais, que na maioria das vezes retornava para seus países de origem ou mesmo em investimento de maior segurança, como por exemplo o ouro, conforme demonstram as tabelas 5, 6 e 7:

Tabela 5: Estatísticas descritivas básicas das ações do setor automotivo do período entre julho e dezembro de 2008

\begin{tabular}{l|ccccccc}
\hline \multicolumn{1}{c}{} & \multicolumn{7}{c}{ Ações } \\
\cline { 2 - 8 } \multicolumn{1}{c|}{ CAT.MX } & RAPT4.SA & FRAS4 & IOCJY & F & TM & HMC \\
\hline Sharpe & 0,2476 & 0,1634 & 0,0926 & 0,1987 & 0,1056 & 0,0810 & 0,0940 \\
Sortino (Downside Risk) & 0,7216 & 0,2734 & 0,3358 & 0,3733 & 0,2320 & 0,2127 & 0,2039 \\
\hline
\end{tabular}

Fonte: Elaboração da Autora.

Tabela 6: Estatísticas descritivas básicas das ações do setor automotivo do período entre janeiro e junho de 2009

\begin{tabular}{l|ccccccc}
\hline \multicolumn{1}{c}{} & \multicolumn{7}{c}{ Aç̃̃es } \\
\cline { 2 - 8 } \multicolumn{1}{c|}{ CAT.MX } & RAPT4.SA & FRAS4 & IOCJY & F & TM & HMC \\
\hline Sharpe & 0,1440 & $-0,1052$ & $-0,0410$ & $-0,1296$ & $-0,1190$ & $-0,0364$ & $-0,0548$ \\
Sortino (Downside Risk) & 0,1361 & $-0,1965$ & $-0,1271$ & $-0,2139$ & $-0,1787$ & $-0,1177$ & $-0,1305$ \\
\hline
\end{tabular}

Fonte: Elaboração da Autora.

Tabela 7: Estatísticas descritivas básicas das ações do setor automotivo do período entre julho e dezembro de 2009

\begin{tabular}{|l|ccccccc}
\hline \multicolumn{1}{c}{} & \multicolumn{7}{c}{ Ações } \\
\cline { 2 - 8 } \multicolumn{1}{c|}{ CAT.MX } & RAPT4.SA & FRAS4 & IOCJY & F & TM & HMC \\
\hline Sharpe & $-0,2325$ & $-0,1894$ & $-0,0419$ & $-0,1661$ & $-0,1463$ & $-0,0706$ & $-0,0932$ \\
Sortino (Downside Risk) & $-0,2916$ & $-0,2923$ & $-0,1109$ & $-0,2433$ & $-0,2455$ & $-0,1930$ & $-0,2154$ \\
\hline
\end{tabular}

Fonte: Elaboração da Autora

Já no final do segundo semestre de 2009, diante da recuperação de vários setores da economia brasileira, observou-se que as ações setor automotivo apresentava um desempenho positivo gerando grandes expectativas para 2010. Foi no primeiro semestre de 2010, que se confirmou as expectativas cogitadas no último semestre, onde as ações RAPT4.SA, FRAS4, IOCJY, F, TM e HMC, apresentaram desempenho positivo de acordo com análise de performance do índice de Sharpe e Sortino. É oportuno ressaltar que apenas CAT.MX apresentou desempenho abaixo do esperado pelo o mercado, tanto pela análise feita a partir do índice de Sharpe, quanto por Sortino, conforme demonstra a tabela 8:

Tabela 8: Estatísticas descritivas básicas das ações do setor automotivo do período entre janeiro e junho de 2010

\begin{tabular}{l|ccccccc}
\hline & \multicolumn{7}{c}{ Ações } \\
\cline { 2 - 8 } & CAT.MX & RAPT4.SA & FRAS4 & IOCJY & F & TM & HMC \\
\hline Sharpe & $-0,0145$ & 0,0849 & 0,0577 & 0,0291 & 0,0163 & 0,0914 & 0,0873 \\
Sortino (Downside Risk) & $-0,0502$ & 0,3234 & 0,1292 & 0,0609 & 0,0819 & 0,1972 & 0,1805 \\
\hline
\end{tabular}

Fonte: Elaboração da Autora

Baseado no cenário econômico que compreende o período de 2006 a 2010, percebeu-se que as ações oscilaram de acordo com a fragilidade e as incertezas da economia, gerando resultados positivos ou negativos conforme sinalizava o mercado.

\section{CONSIDERAÇÕES FINAIS}

Diante de um cenário econômico externo fragilizado, após o estouro da bolha de hipotecas imobiliárias nos EUA em 2007, se instaurou um clima de incertezas, logo investidores de diversos lugares do mundo começaram a retirar seus investimentos, com esse movimento no sistema financeiro, logo surgiu o problema de liquidez no mercado, gerando incertezas quanto à economia no âmbito mundial.

Acreditavam que o Brasil não teria grandes problemas com a crise que se originou nos Estados Unidos, uma vez que as instituições financeiras do país garantiram que não possuíam títulos de alto risco "subprime", além desse fator outro ponto bastante relevante se dá no fato do Brasil está bem preparado quanto às políticas fiscais, devido o país ter sido afetado pela falta de liquidez em 1999 causada pela crise asiática, afetando inclusive o setor automotivo naquele ano.

Contudo, empiricamente deduz-se que o setor automotivo brasileiro não sofreu grandes impactos com a crise econômica mundial, uma vez que o setor automotivo de outros países a exemplo Estados Unidos e Japão apresentaram resultados negativos nas vendas e na produção de veículos, onde grandes fabricantes do setor recorreram aos governos locais para não abrirem falência. No entanto, diante de um cenário tão fragilizado o setor automotivo brasileiro, mesmo não atingindo os resultados projetados, mas fechou aqueles anos de recessão com resultados positivos. 
Considerando a proposta deste trabalho de pesquisa, grande parte dos resultados obtidos neste setor se deu devido a grande intervenção do governo, visando manter os vários setores da economia aquecidos e principalmente o setor automotivo, visando inclusive atenuar a taxa de desemprego, principalmente pelas montadoras do setor, para tanto o governo teve que abdicar o recolhimento do IPI em um dado momento em sua parcialidade e em outro na sua totalidade, gerando um déficit para os cofres públicos.

Diante do exposto, e a partir de análises de desempenho financeiro de ações do setor objeto deste estudo, usando como parâmetro métricas de performance de índice de Sharpe e Sortino, conclui-se que o setor automotivo brasileiro foi afetado negativamente pela crise econômica mundial "subprime", porém os impactos financeiros sofridos pela indústria automotiva não foi claramente percebida devido o governo federal ter trabalhado intensamente, visando manter o aquecimento da economia, com isso se explica o fato de que o maior volume de vendas no período de crise se deu dentro do próprio país, uma vez que o decréscimo nas exportações de autoveículos foi facilmente percebido.

Diante das limitações desta pesquisa e considerando que a economia brasileira sempre foi tida como volátil, e considerando ainda que a economia não tem um bom histórico de estabilidade financeira, mas que possui uma grande potencialidade no setor automotivo sugere-se que outros pesquisadores se aprofundem mais no assunto aqui discutido, visando contribuir para o desenvolvimento do setor automotivo, bem como para o desenvolvimento da economia do país.

\section{REFERÊNCIAS}

1. MATOS, Paulo; SOARES, Osair. Análise Estatística do Efeito da Crise Financeira de 2007 no setor de veículos e transportes no Brasil. Fortaleza, 2010. 54 p. CAEN -

Universidade Federal do Ceará, Fortaleza, 2010.

\section{REBOUÇAS, Fernando. Indústria Automobilística no}

Brasil. Infoescola, 2011. Disponível em:

<http://www.infoescola.com/economia/industriaautomobilistica-no-brasil/> . Acesso em: 03 set. 2013.

3. ROUBINI, Nouriel; Stephen Mihm; tradução ARAÚJO, Carlos. A economia das crises: Um curso-relâmpago sobre o futuro do sistema financeiro internacional. - Rio de Janeiro: Intrínseca, 2010. 368 p.

4. PINHEIRO, Juliano Lima. Mercado de Capitais:

Fundamentos e Técnicas. - 5 ed. - São Paulo: Atlas, 2009.

5. LIMA, J. E. C. Os Impactos da Crise Financeira de 2008 nas Ações das Instituições Brasileiras. Juazeiro do Norte, 2012. 71 p. Dissertação (Mestrado Profissional em Economia) - Universidade Federal do Ceará, Fortaleza, 2012. [Orientador: Prof. Dr. Rogério Faustino Matos].

6. BRASIL. Banco Central do Brasil. Relatório de Estabilidade Financeira. Brasília: BCB, 2008 - V.7. N. 2. P. 1-174. Nov. 2008. ISSN 1677 - 812X.

7. BRASIL. Tribunal de Contas da União. Relatório e Parecer Prévio sobre as Contas do Governo da República. Brasília, 2008 - V. Anual.

8. BM\&FBOVESPA. Relatório Anual 2009. São Paulo.

9. ANFAVEA. Anuário Estatístico da Indústria Automobilística Brasileira. São Paulo, Associação Nacional dos Fabricantes de Veículos Automotores, 2013.

10. SINDIPEÇAS. Desempenho do Setor de Autopeças. São Paulo, Sindicato Nacional da Indústria de Componentes para Veículos Automotores, 2013. 